\title{
Food intake and diet selection in sheep: the effect of manipulating the rates of digestion of carbohydrates and protein of the foods offered as a choice
}

\author{
BY I. KYRIAZAKIS AND J. D. OLDHAM \\ Genetics and Behavioural Sciences Department, Scottish Agricultural College Edinburgh, \\ West Mains Road, Edinburgh EH9 $3 J G$
}

(Received 21 December 1995 - Revised 10 June 1996 - Acccepted 19 June 1996)

\begin{abstract}
An experiment was designed to investigate whether the degree of synchrony between the rates of digestion of carbohydrates and $\mathbf{N}$ of foods offered as a choice would have an effect, through their consequences, on the short- and long-term diet selection of sheep. Four foods $\left(R_{L}, R_{H}, S_{L}\right.$ and $\left.S_{H}\right)$ with the same high metabolizable energy, and similar high metabolizable protein contents were made into pellets. Foods $R_{L}$ and $R_{H}$ were based on a rapidly fermentable carbohydrate source and foods $S_{L}$ and $S_{H}$ on a slowly fermentable carbohydrate source; within each source one food $\left(R_{L}\right.$ or $S_{L}$ ) had a low, and the other $\left(R_{H}\right.$ or $\left.S_{B}\right)$ a high, rumen-degradable protein (RDP) content. The foods within a carbohydrate source were offered either singly or as a choice $\left(R_{L} / R_{H}\right.$ or $\left.S_{L} / S_{H}\right)$ to eleven rumen-fistulated mature sheep. The design was two $3 \times 3$ Latin squares (replicated once) with 5week periods; squares consisted of two single foods and their respective choice. Weeks 1,3 and 5 were considered to be controls, and weeks 2 and 4 used for rumen infusions of either urea or fructose infused over $4 \mathrm{~h}(10.00-14.00$ hours). Food intake (FI) and diet selections (DS) were recorded daily and every $2 \mathrm{~h}\left(08.00-16.00\right.$ hours) on days $2-5$ of each week; rumen $\mathrm{pH}$ and $\mathrm{NH}_{3}$ concentrations were also measured during these time intervals of day 5 . As expected, feeding treatment affected significantly the rumen measurements: rumen $\mathrm{NH}_{3}$ concentrations were higher on foods $R_{H}$ and $S_{H}$, and rumen pH lowest on $R_{L}$. Daily FI was lowest on treatments $S_{L}$ and choice $S_{\mathrm{L}} / \mathbf{S}_{\mathrm{H}}$. The mean daily proportion of the low-RDP food in the selected diet was lower when the carbohydrate source was rapidly (choice $R_{L} / R_{H}$ ) rather than slowly fermentable (choice $S_{L} / S_{H}$ ); this was consistent with the experimental hypothesis. Short-term infusions affected further rumen variables (in the expected directions), irrespective of feeding treatment. However, DS over the $4 \mathrm{~h}$ infusion period were unaffected; these short-term DS were consistent with the ones selected over the longer term (daily). The results suggest that the long-term (daily) diet selection of sheep may be affected by the degree of synchrony of energy and protein to the rumen. The fact that diet selections were not altered further by short-term manipulations of these supplies might reflect inadequacies of the methodology (infusions) adopted here.
\end{abstract}

Diet selection: Food intake: Rumen: Rumen-degradable protein: Sheep

It has been suggested that one of the objectives of the diet selection of ruminant animals is to maintain a fit and adaptive rumen (Cropper, 1987; Parsons et al. 1994; Cooper et al, $1995 b$ ). This strategy would be expected to assist the animal in achieving its ultimate goal of meeting its requirements for energy and nutrients, and would require certain aspects of the rumen environment to remain at optimal levels or at least within an acceptable range of conditions. Cooper et al. $(1995 a, b)$ hypothesized that the rumen conditions that may have a significant effect on the diet selection of ruminants would be those related to the consequences of fermentation of rapidly fermentable materials (such as increased acidity and osmolality) and the hydrolysis of rapidly degradable protein (high concentrations of $\mathrm{NH}_{3}$ ). 
Some information on how the separate consequences of fermentation of rapidly fermentable carbohydrates, and rapidly degradable protein affect the diet selection of ruminants is now available. It has been found, for example, that sheep adjust their diet selection between two foods of different energy density according to the acidity and osmolality of the rumen contents (Engku Azahan \& Forbes, 1992; Cooper et al. 1995a,b). In addition, their diet selection from foods of different rumen-degradable protein contents appears to be such that they minimize excess of rapidly degradable $\mathrm{N}$ (Kyriazakis \& Oldham, 1993; Cooper et al. 1994). It is, however, well established that the rumen conditions and their possible consequences can be affected by the interactions (degree of synchrony) between the rates of fermentation of carbohydrates and degradation of protein (Visek, 1968). It could, therefore, be hypothesized that the diet selection of ruminants from two foods of different rapidly degradable protein contents could be affected by the rate of their carbohydrate fermentation. The objective of the experiment reported here was to investigate this hypothesis in relation to the short- and long-term diet selection of sheep. The differences in the rate of synchrony between carbohydrate fermentation and degradation of protein were achieved through dietary manipulations or by infusion of rapidly fermentable and/or degradable substances.

\section{MATERIALS AND METHODS}

\section{Animals and housing}

Twelve Scottish Greyface female sheep, aged 20-24 months and weighing 59.1 (SD 7.16) $\mathrm{kg}$ were intended to be used. Each animal was fitted with a rumen cannula under surgical anaesthesia $\left(\mathrm{O}_{2}\right.$-halothane general anaesthesia), 6 months before the start of the experiment. During the experiment the sheep were kept in metabolism cages, placed in a naturally ventilated room, and given a minimum of $16 \mathrm{~h}$ light daily. The sheep had been given prior experience of the cages, the procedures to be used and the experimental routine during a $14 \mathrm{~d}$ pilot study. They had, however, no prior experience of the experimental foods. Just before the start of the experiment one animal developed respiratory problems and had to be excluded from the main part of the experiment.

\section{Foods}

Four experimental foods were formulated and made into pellets (Table 1). Two of the foods were based on a rapidly fermentable carbohydrate source (barley; $R$ foods) and the other two on a slowly fermentable carbohydrate source (unmolassed sugarbeet pulp; $S$ foods). Within each pair of foods ( $R$ or $S$ ) one contained a low and the other a high concentration of effective rumen-degradable protein (eRDP; Agricultural and Food Research Council, 1992); the eRDP contents of the foods are denoted by the subscripts $\mathrm{L}$ and $\mathrm{H}$ respectively. The high eRDP was achieved by the replacement of part of the carbohydrate source of the low eRDP foods with a mixture of rapeseed and sunflowerseed meals, and dried skimmed milk (approximately $3: 3: 1$ respectively). As a consequence, $H$ foods contained less of the fermentable carbohydrate source than the $L$ foods. It was therefore expected that the difference in the fermentability characteristics would be higher between the $\mathrm{L}$ foods than the $\mathrm{H}$ foods.

All four foods had relatively high concentrations of metabolizable energy (ME), protein (MP) and macrominerals (Agricultural and Food Research Council, 1993), so that consumption of the foods at a level to meet ME requirements would be possible and also allow MP and mineral requirements to be met. The MP content of the foods was calculated using the system proposed by the Agricultural and Food Research Council 
Table 1. The ingredients and chemical composition ( $\mathrm{g} / \mathrm{kg}$ fresh food) of the four experimental foods

\begin{tabular}{|c|c|c|c|c|}
\hline & \multicolumn{4}{|c|}{ Food } \\
\hline & $R_{L}$ & $\mathbf{R}_{\mathbf{H}}$ & $S_{L}$ & $S_{H}$ \\
\hline \multicolumn{5}{|l|}{ Ingredients $(\mathrm{g} / \mathrm{kg})$} \\
\hline Barley & 710 & 355 & - & - \\
\hline Unmolassed sugarbeet pulp & - & - & 654 & 331 \\
\hline Oatfeed & 187 & 120 & 207 & 140 \\
\hline Rapeseed meal & - & 200 & 53 & 233 \\
\hline Sunflowerseed meal & - & 180 & 47 & 213 \\
\hline Dried skimmed milk & - & 57 & 16 & 67 \\
\hline CMS 20* & 70 & 70 & - & - \\
\hline Salt & 3.4 & $5 \cdot 3$ & $2 \cdot 0$ & 3.1 \\
\hline Dicalcium phosphate & 13.9 & - & 17.7 & - \\
\hline Limestone flour & $8 \cdot 2$ & $10 \cdot 8$ & - & 9.9 \\
\hline Calcined magnetise & $2 \cdot 3$ & - & 1.7 & - \\
\hline Sodium sulphate & 3.6 & - & - & - \\
\hline Mineral and vitamin mix $\dagger$ & $2 \cdot 0$ & $2 \cdot 0$ & $2 \cdot 0$ & $2 \cdot 0$ \\
\hline \multicolumn{5}{|l|}{ Chemical composition $(\mathrm{g} / \mathrm{kg})$} \\
\hline Dry matter & 878 & 882 & 896 & 885 \\
\hline Degradability (\%) & 88.3 & 89.4 & 80.8 & 85.0 \\
\hline $\mathrm{ME}(\mathrm{MJ} / \mathrm{kg}) \ddagger$ & 9.6 & 9.6 & 9.6 & 9.6 \\
\hline $\mathrm{fME}(\mathrm{MJ} / \mathrm{kg}) \S$ & 8.5 & $8 \cdot 5$ & 8.8 & 8.6 \\
\hline Crude protein & 87 & 181 & 102 & 179 \\
\hline eRDP\$ & 69 & 145 & 76 & 139 \\
\hline Microbial protein (DMTP)§ & 44 & 54 & 49 & 55 \\
\hline Metabolizable protein (MP) $\S$ & 53 & 70 & 65 & 78 \\
\hline Neutral-detergent fibre & 275 & 289 & 378 & 354 \\
\hline Ash & 57 & 61 & 188 & 188 \\
\hline Calcium & 9.5 & $7 \cdot 8$ & $13 \cdot 1$ & 11.8 \\
\hline Phosphorus & 5.8 & 5.8 & 6.5 & $5 \cdot 1$ \\
\hline Sodium & $2 \cdot 7$ & 3.1 & 1.1 & 1.6 \\
\hline Sulphur & 2.4 & 3.0 & 2.7 & $3 \cdot 7$ \\
\hline
\end{tabular}

ME, metabolizable energy; fME, fermentable ME; eRDP, effective rumen degradable protein; DMTP, digestible microbial true protein.

* Condensed molasses solubles, blended with $200 \mathrm{~g}$ cane molasses/kg (Intermol, Cobham, Surrey).

† Scotmin ewe/lamb mixture (Scotmin Nutrition Ltd, Ayr, Scotland).

$\mp$ Calculated from standard food tables.

$\S$ Values calculated using the MP system (Agricultural and Food Research Council, 1992) assuming a rumen outflow rate of $0.05 / \mathrm{h}$.

(1992) and the ME was estimated from standard food tables (see Table 1). The degradability characteristics of all four foods were determined on three rumen-fistulated steers, with food samples kept in their rumen for up to $72 \mathrm{~h}$. There were eight incubation times: $0,2,4,8,16,24,48$ and $72 \mathrm{~h}$, and two samples were taken per animal at each incubation time. The degradability coefficients obtained this way were used to calculate the eRDP and MP contents of all foods (Table 1), according to the Agricultural and Food Research Council (1992) system.

\section{Experimental design}

Each of the two foods based on the same carbohydrate source ( $R$ or $S$ ) was offered either ad libitum singly or as a choice to six (five in the case of the $S$ foods) sheep in a $3 \times 3$ Latin 
square arrangement replicated once (i.e. one Latin square consisted of feeding treatments $R_{L}, R_{H}$ and their choice $R_{L} / R_{H}$, and the other of treatments $S_{L}, S_{H}$ and choice $S_{L} / S_{H}$ ); each of the six possible sequences of the treatments was used. Each of the Latin square periods was 5 weeks long: the first week was considered to be the period of adaptation on the feeding treatments. The second and fourth weeks were periods where the infusion treatments were applied, and the third and fifth weeks were intervals to avoid any residual (carry-over) effects of the infusion treatments.

The infusion treatments were rumen infusions of either $10 \mathrm{~g}$ urea or $50 \mathrm{~g}$ fructose diluted in 1 litre of distilled water, and were administered to the sheep over a $4 \mathrm{~h}$ period (10.00-14.00 hours) on four consecutive days (2-5) of each of the infusion weeks. The order of application of urea or fructose as infusions was randomized across sheep. Fructose and urea were chosen as sources of rapidly fermentable carbohydrates and rapidly degradable $\mathrm{N}$ respectively; their levels of infusion were investigated in a preliminary trial and the ones chosen were those that would cause significant changes to the rumen environment measured as effects on $\mathrm{pH}$ or accumulation of $\mathrm{NH}_{3}$ and/or $\mathrm{NH}_{4}{ }^{+}$.

\section{Management and measurements}

At the start of the experiment all animals were given a training period of $10 \mathrm{~d}$ in which the two foods to be offered in the Latin square arrangement were offered alone on alternate days. This regimen was used according to the methodology of Kyriazakis \& Oldham (1993).

The live weight of the sheep was measured on the first day of each Latin square block, before feeding. Food refusals were removed, weighed and discarded, and fresh food offered at 08.00 hours each day. On days 2-5 of each week food intake was measured every $2 \mathrm{~h}$ between 08.00 and 16.00 hours, by removing the troughs, weighing and returning them to the pens. The rumen infusates were administered via a piece of semi-rigid PVC tubing (i.d. $3 \mathrm{~mm}$ ) inserted through a rumen cannula bung. On the fourth day of each week (day 5), samples of about $80 \mathrm{ml}$ rumen contents were withdrawn at $08.00,10.00,12.00$, 14.00 and 16.00 hours. The 08.00 hours sample was taken before offering the fresh food(s), but after the restoration of light. To take rumen samples, a stiff piece of tubing was inserted through the rumen cannula bung, which was adjacent to the infusion tubing but did not touch it. The rumen content samples were withdrawn using a hand-held pump, and collected into glass containers. Efforts were made to collect the samples from the same parts of the rumen-reticulum (different sampling sites) at each sampling time.

\section{Sample processing and analysis}

The rumen samples were analysed for $\mathrm{pH}$ (used as an indicator of carbohydrate fermentation) and $\mathrm{NH}_{3}-\mathrm{N}$ concentrations. The $\mathrm{pH}$ of each sample was measured immediately after sampling using a glass electrode. The rumen contents were then strained through double-thickness muslin and the $\mathrm{NH}_{3}-\mathrm{N}$ concentration in the strained liquid was measured subsequently, using an ion-selective electrode (EIL Analytical Instruments Ltd, Chertsey, Surrey).

\section{Statistical analysis}

Data from days 2-5 only of each experimental week were considered for the analyses of the food intake and diet selection results. These data were tested for any developing time trends, and since no such trends were found the means of those $4 \mathrm{~d}$ were used for further 
analyses. The whole experiment (i.e. both food series) was considered as a single design and analysed by the use of the residual maximum likelihood (REML; Robinson, 1987) since it was imbalanced (unequal numbers of animals per carbohydrate source series/Latin squares). REML also allowed contemporaneous comparisons to be made within and between sheep.

Daily food intake and the proportion of the low eRDP ( $g$ food $R_{L}$ or $S_{L} / k g$ total food intake (TFI)) selected were analysed with feeding treatment and infusion treatment as factors (there were considered to be five such treatments: adaptation, urea, post-urea fructose and post-fructose). These data were then divided into time intervals (08.00-10.00 hours, (pre-infusion interval), 10.00-14.00 hours (infusion interval), 14.00-16.00 hours (immediate post-infusion interval) and 16.00-08.00 hours) which were analysed separately, using the previously mentioned factors. The $\mathrm{pH}$ and $\mathrm{NH}_{3}-\mathrm{N}$ data (collected on day 5 of each week) were treated in a similar manner to the food intake and diet selection data (i.e. each sampling time was analysed separately).

The diet selection data were tested for normality and since they met the criteria for normal distribution they were not transformed by any means for the purposes of the analyses. The transformed $\mathrm{pH}$ values were used in the analyses, but they had to be untransformed for the calculation of the means.

\section{RESULTS}

Data were not collected from three sheep over the last 1-2 weeks of the experiment due to problems with their cannulas. These sheep were on feeding treatments $R_{L}, R_{L} / R_{H}$ and $S_{L} /$ $S_{\mathrm{H}}$. Their food intake, diet selection and rumen measurements over these weeks were treated as missing values. There were no differences between the three non-infusion treatments (i.e. adaptation, post-urea and post-fructose) in all measurements taken. For this reason data from these treatments were considered to belong to one treatment, hence called control (or no infusion).

\section{Daily food intake and diet selection}

There were no effects of infusion, or infusion $\times$ feeding treatment interactions on the daily food intake and the diet selection; therefore values presented here are the averages over the whole 5-week experimental period. Feeding treatment, however, significantly $(P<0.05)$ affected food intake: $1604,1599,1675,1428,1718$ and 1488 (SED 124) g/d for treatments $R_{L}, R_{H}, R_{L} / R_{H}, S_{L}, S_{H}$ and $S_{L} / S_{H}$ respectively. The effect was thus mainly due to the lower food intakes on treatments $S_{L}$ and choice $S_{L} / S_{H}$.

The mean daily proportion of the low eRDP food in the selected diet clearly tended $(0.1>P>0.05)$ to be lower when the carbohydrate source was rapidly (choice $R_{L} / R_{H}$ ) rather than slowly fermentable (choice $S_{L} / S_{H}$ ): $396 \mathrm{~g} \mathrm{R}_{\mathrm{L}}$ and $611 \mathrm{~g} \mathrm{~S}_{\mathrm{L}} / \mathrm{kg}$ TFI (SED 118) for the two food choices respectively (Table 2 ).

\section{Rumen measurements}

The interaction between infusion and feeding treatments was not significant for any of the rumen measurements taken. There was a significant effect of feeding treatment on rumen $\mathrm{NH}_{3}$ concentrations at all sampling times of the experiment $(P<0.001$; Fig. 1). As expected, the $\mathrm{NH}_{3}$ concentrations were higher on foods $\mathbf{R}_{\mathrm{H}}$ and $\mathrm{S}_{\mathrm{H}}$ (high eRDP contents) than on foods $R_{L}$ and $S_{L}$ (low eRDP contents). The $\mathrm{NH}_{3}$ concentrations of the animals offered a choice between two foods were in-between and reflected their diet selections; 
Table 2. The proportion (prop) of the low effective rumen-degradable protein (eRDP) food selected per $\mathrm{kg}$ total food intake (TFI) by sheep given a choice between two foods based either on a rapidly $(R)$ or a slowly $(S)$ fermentable carbohydrate source which differed in their $e R D P$ contents: low (food $R_{L}$ or $S_{L}$ ) and high (food $R_{H}$ or $\left.S_{H}\right) \dagger$

\begin{tabular}{lccccc}
\hline \hline & \multicolumn{5}{c}{ Time of day (hours) } \\
\cline { 2 - 6 } & $08.00-10.00$ & $10.00-14.00$ & $14.00-16.00$ & $16.00-08.00$ & Daily \\
\hline Prop $R_{L}$ or $S_{L}$ selected & & & & \\
$\quad\left(g R_{L}\right.$ or $S_{L} / k g$ TFI) $\neq$ & 250 & 396 & 387 & 455 & 396 \\
Prop $R_{L}$ & 688 & 645 & 662 & 583 & 611 \\
$\quad$ Prop $S_{L}$ & 114 & 144 & 121 & 131 & 118 \\
SED & $* * *$ & $0.1>P>0.05$ & $*$ & NS & $0.1>P>0.05$ \\
Significance & & &
\end{tabular}

$* P<0.05, * * * P<0.001$.

† For details of diets and procedures, see Table 1 and pp. 244-247.

$\ddagger$ The values are means, across infusion treatments, over the whole 5-week experimental period.

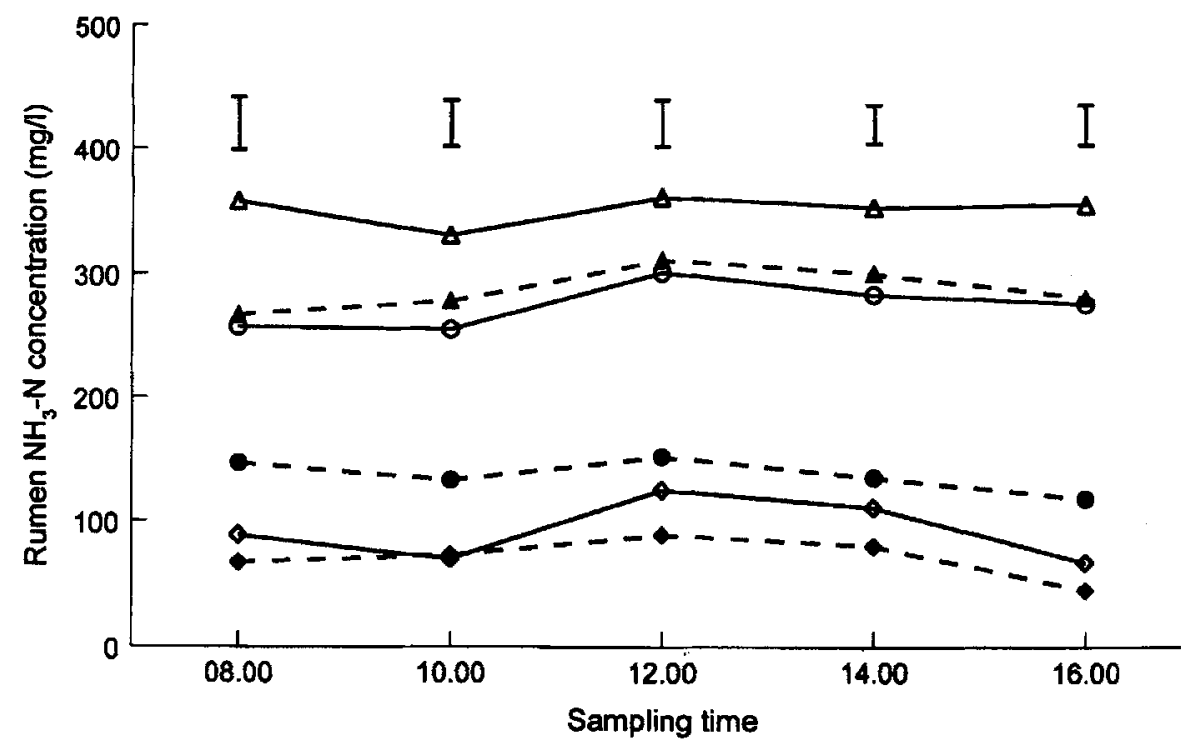

Fig. 1. The $\mathrm{NH}_{3}-\mathrm{N}$ concentrations (mg/) of the rumen contents, measured over the period $08.00-16.00$ hours (samples taken every $2 \mathrm{~h}$ ) of rumen-fistulated sheep given access to: a low effective rumen-degradable protein (eRDP) food $(\diamond, \diamond)$, a high eRDP food $(\Delta, \Delta)$ or a choice between the two foods $(\Theta, O)$. The foods were based either on slowly $(\diamond, \boldsymbol{\Lambda}, \diamond)$ or rapidly $(\diamond, \Delta, \bigcirc)$ fermentable carbohydrates. The error bars are the standard errors of the difference between feeding treatments. For details of foods and procedures, see Table 1 and pp. 244-247.

however, they were different between these two feeding treatments (choice $R_{L} / R_{H} v$. choice $\left.S_{L} / S_{H}\right)$. The effect of feeding treatment on rumen $\mathrm{pH}$ was significant only at 08.00 (pre-infusion) and 14.00 hours (end of infusions) sampling times (Fig. 2); the values in Fig. 2 are the averages over the whole 5-week experimental period. Thus, feeding on the loweRDP food based on a rapidly fermentable carbohydrate source, food $R_{L}$, resulted in the lowest rumen $\mathrm{pH}$. 


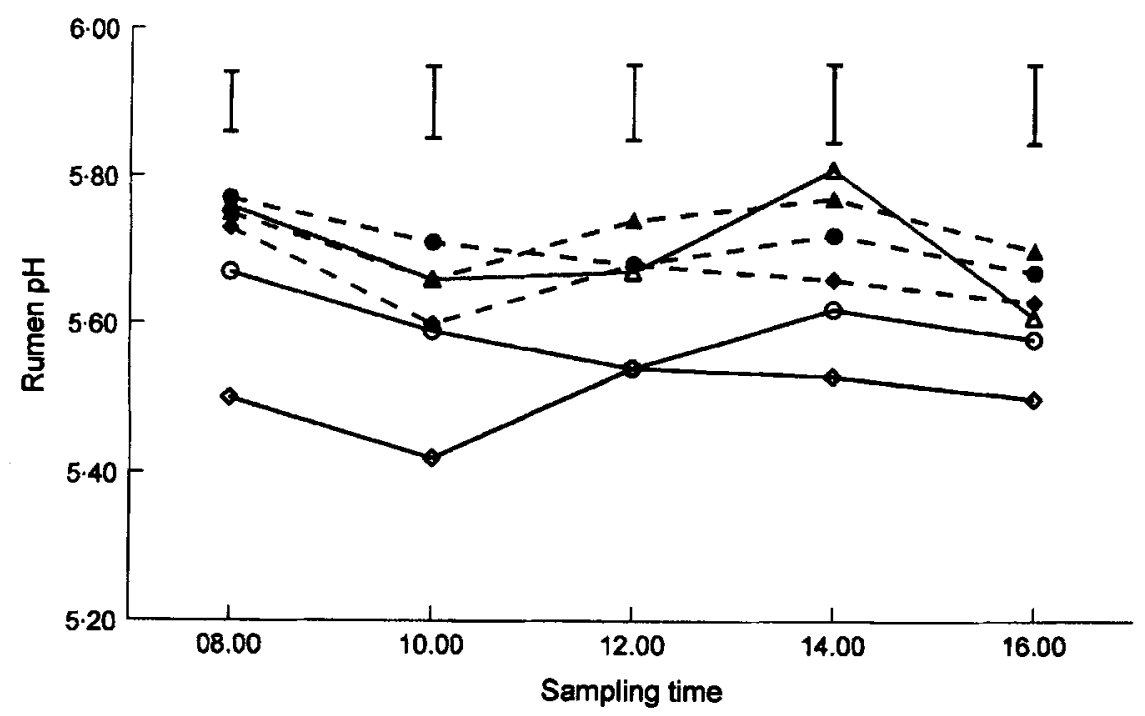

Fig. 2. The pH of the rumen contents, measured over the period 08.00-16.00 hours (samples taken every 2 h) of rumenfistulated sheep given access to: a low effective numen-degradable protein (eRDP) food $(\diamond, \diamond)$, a high eRDP food $(\Delta, \Delta)$ or a choice between the two foods $(\Theta, O)$. The foods were based either on slowly $(\bullet, \Delta, \Theta)$ or rapidly $(O, \Delta, O)$ fermentable carbohydrates. The error bars are the standard errors of the difference between feeding treatments. For details of foods and procedures, see Table 1 and pp. 244-247.

The effects of infusion treatments on the rumen $\mathrm{NH}_{3}$ concentrations and $\mathrm{pH}$ at all sampling times are shown in Fig. 3. The infusion of urea into the rumen increased $\mathrm{NH}_{3}$ concentrations whereas that of fructose reduced them; both these effects were highly significant at sampling times $10.00,12.00$ and 14.00 hours $(P<0.001)$, i.e. during the infusion. The effect of the urea infusion on $\mathrm{NH}_{3}$ concentration persisted for $2 \mathrm{~h}$ after the end of the infusion $(16.00$ hours sampling time; $P<0.001)$. Rumen $\mathrm{pH}$ was similarly increased by urea and decreased by fructose rumen infusions (the effects were highly significant at sampling times 10.00 and 12.00 hours). The effect of the infusions on rumen $\mathrm{pH}$ tended to be more transient than the effect on $\mathrm{NH}_{3}$ concentration, since it was not present $2 \mathrm{~h}$ after the infusion had been terminated (16.00 hours sampling time).

\section{Short-term food intake and diet selection}

There was no interaction between infusion and feeding treatment on the food intake consumed and diet selection during each time interval considered. Food intake over the specific time intervals $(08.00-10.00,10.00-14.00,14.00-16.00$ and 16.00-08.00 hours) was unaffected by feeding treatment. However the feeding treatment effect seen on the daily food intake tended to be evident during the latter three time intervals, but not during the period $08.00-10.00$ hours. For example, food intakes over the time intervals $10.00-$ 14.00 and 14.00-16.00 hours were 236, 214, 253, 203, 204, 214 and 165, 177, 172, 145, $183,144 \mathrm{~g}$ for treatments $R_{L}, R_{H}, R_{L} / R_{H}, S_{L}, S_{H}$ and $S_{L} / S_{H}$ respectively. However, they were $176,199,202,226,221$ and $188 \mathrm{~g}$ respectively for the time interval $08.00-10.00$ hours. Food intake during the $4 \mathrm{~h}$ of infusion was significantly affected $(P<0.001)$ by the infusion treatment administered (Table 3): this effect was due to the reduction in food 

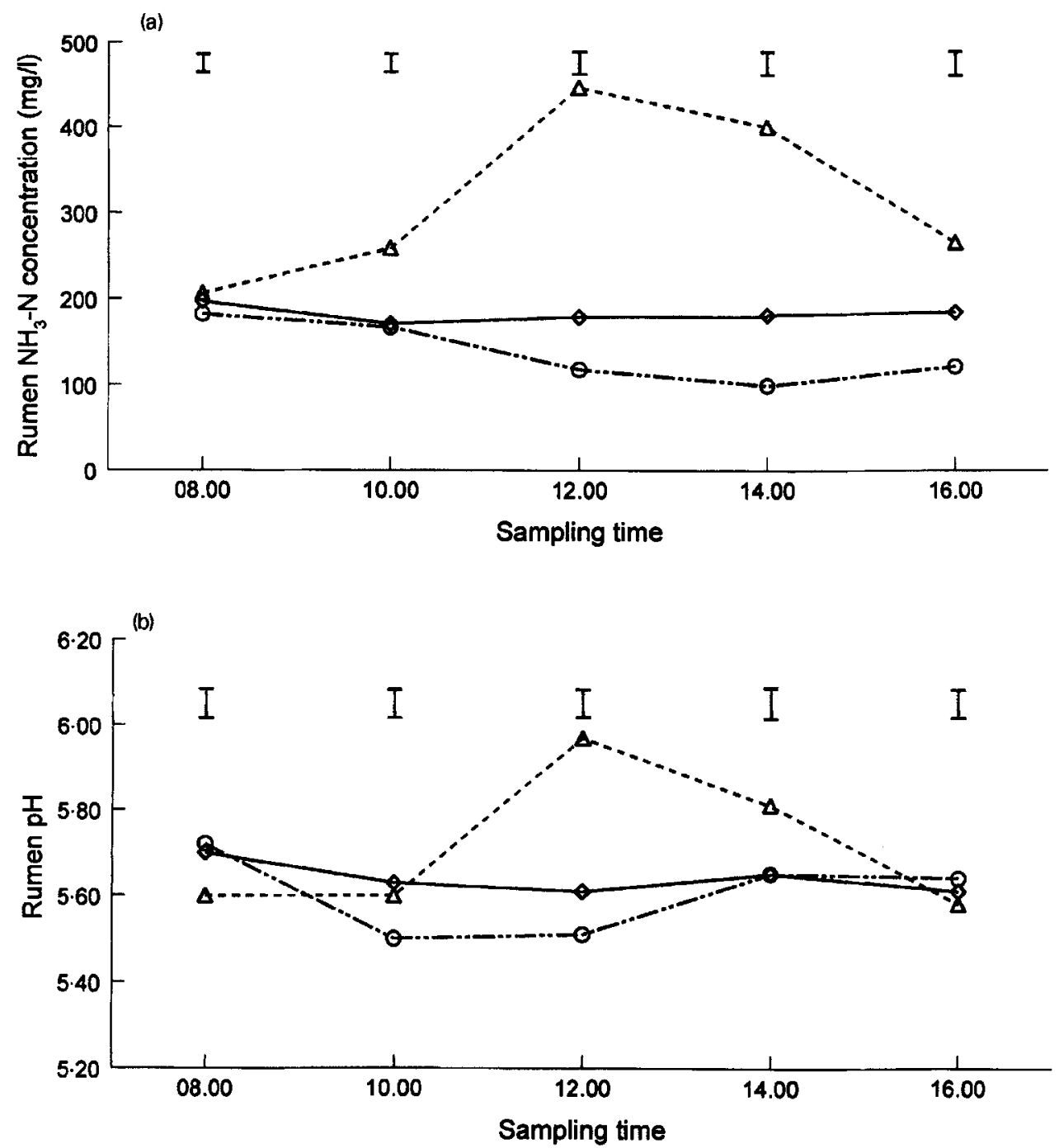

FIg. 3. The effects of infusion of urea $\left(-\Delta_{-}\right)$, fructose $\left(-O_{-}\right)$or nothing (controls, $\left.-\diamond_{-}\right)$over a 4 h period $(10.00-14.00$ hours) on mean (a) $\mathrm{pH}$ and (b) $\mathrm{NH}_{3}-\mathrm{N}$ concentrations $(\mathrm{mg} / \mathrm{l}$ ) of the rumen contents of rumen-fistulated sheep. Rumen samples were taken every $2 \mathrm{~h}$ over the period $08.00-16.00$ hours, and the means are across feeding treatments. The error bars are the standard errors of the difference between infusion treatments. For details of procedures, see pp. $244-247$.

intake caused by the infusion of fructose. The effect of infusion treatment on food intake was only temporary (i.e. it was not present during the $2 \mathrm{~h}$ interval following the infusion).

The diet selection of the sheep, during the time intervals considered, was affected by the carbohydrate source of the food pair (Table 2). The pattern of the effect was in the same direction as the one seen during mean daily diet selection; however, no formal comparison between time intervals were made. The infusions of urea or fructose did not have any significant effects on the diet selections (proportions of the low-eRDP food in the selected diet) during any of the time intervals considered. 
Table 3. The effects of infusion treatments, administered between 10.00 and 14.00 hours every day, on the short-term and daily rate of food intake $(\mathrm{g})$ of sheep $\dagger$

\begin{tabular}{lccccc}
\hline & \multicolumn{5}{c}{ Food intake $(\mathrm{g})$} \\
\cline { 2 - 6 } Time of day (hours) ... & $08.00-10.00$ & $10.00-14.00$ & $14.00-16.00$ & $16.00-08.00$ & Daily \\
\hline Infusion treatment+ & & & & & \\
Control (no infusion) & 200 & 23 & 160 & 992 & 1592 \\
Urea & 210 & 238 & 171 & 997 & 1613 \\
Fructose & 201 & 198 & 169 & 956 & 1524 \\
SED & $12 \cdot 3$ & 12.6 & 12.7 & 31.9 & $50 \cdot 4$ \\
Significance & $\mathrm{NS}$ & $* * *$ & $\mathrm{NS}$ & $\mathrm{NS}$ & $\mathrm{NS}$ \\
\hline \hline
\end{tabular}

*** $P<0.001$.

$\dagger$ For details of diets and procedures, see Table 1 and pp. 244-247.

¥The values are means, across feeding treatments, over the whole 5-week experimental period.

\section{DISCUSSION}

The objective of the present experiment was to investigate whether the synchrony (or asynchrony) between the rates of digestion of carbohydrates and $\mathrm{N}$, would have an effect (through their consequences) on the diet selection of sheep given a choice between two foods of different eRDP contents: low and high. The differences in the rates of digestion were further exaggerated through the manipulation of the rate of carbohydrate fermentation of the two foods, and the infusion of fructose or urea into the rumen. The effects on diet selection and food intake were measured in both the 'long-term' (daily) and 'short-term' ( $2 \mathrm{~h}$ intervals within a day), and will be considered in this order here. First, we will briefly discuss the results from the animals given access to a single food.

The daily rate of food intake of sheep, whilst on the single foods, was affected by the kind of food they had access to. It was lowest on the food with the highest inclusion rate of sugarbeet pulp ( $650 \mathrm{~g} / \mathrm{kg}$ ), which was also the food with a low eRDP content (food $\mathrm{S}_{\mathrm{L}}$ ). This reduced food intake is considered to be a reflection of the properties of sugarbeet pulp: slow fermentation rates (De Visser, 1993) and importantly, high water-holding capacity (Kyriazakis \& Emmans, 1995); both these properties are considered to be contributors of high bulkiness. Food intake over the short-term time intervals within a day tended to follow the same pattern: animals on food $S_{L}$ tended to consume less food within each time interval. The only exception was the very first time interval within a day $(08.00-10.00$ hours). This interval included the events of restoration of light, following an $8 \mathrm{~h}$ dark period (during which sheep tend to consume very little, if any, food (Newman et al. 1994 and our casual observations)) and the offering of fresh food, which stimulates their intake (Forbes, 1995). It is also worth noting that the food intake of the sheep given a choice between the two sugarbeet-pulp-based foods $\left(S_{\mathrm{L}}\right.$ and $\left.S_{H}\right)$ also had a reduced rate of daily food intake, especially in relation to the animals given access to food $S_{H}$ alone; this was an outcome of their diet selection (a diet that consisted largely of food $S_{L}$ ). They could have achieved a higher food intake had they selected a higher proportion of food $S_{H}$ (see p. 252). This finding is consistent with our previously expressed view (Cooper et al. 1995b; Emmans \& Kyriazakis, 1995) that the maximization of the rate of food intake (suggested by Krebs \& McCleery, 1984) might not be the sole objective of the diet selection of ruminants. A similar suggestion to ours, based however on a different hypothesis from the one we offer here, has also recently been proposed by other authors (Ketelaars \& Tolkamp, 1992). 
The daily diet selection of the sheep given a choice between two foods differing in their eRDP contents was affected by the rate of digestion of the carbohydrates in the foods. The proportion of the low eRDP selected clearly tended to be lower when the carbohydrate source of the two foods was rapidly (choice $R_{L} / R_{H}$ ) rather than slowly fermentable (choice $\mathrm{S}_{\mathrm{L}} / \mathrm{S}_{\mathrm{H}}$ ). This feeding behaviour is consistent with the experimental hypothesis and the preliminary indications that animals (1) avoid an excess of eRDP in their diet, if they are given the opportunity (Kyriazakis \& Oldham, 1993; Cooper et al. 1994), but (2) do not select solely the low eRDP food which clearly limits the growth of the rumen microbes. The avoidance of excess eRDP could protect them from an excessive load of $\mathrm{NH}_{3}$. This risk of $\mathrm{NH}_{3}$ escaping into the peripheral circulation is lower when the carbohydrate source of the foods is a rapidly fermentable one, rather than a slowly fermentable one, since in the presence of the former, rumen $\mathrm{NH}_{3}$ resulting from $\mathrm{N}$ degradation can be taken up at a faster rate by the rumen microbes (Oldham et al. 1977; Sinclair et al. 1993, 1995). The fact that the diet selections by $R_{L} / R_{H}$ and $S_{L} / S_{H}$ animals did not result in a certain, similar level of rumen $\mathrm{NH}_{3}-\mathrm{N}$ concentration, should not be taken as contradicting the above suggestions. Rumen $\mathrm{NH}_{3}-\mathrm{N}$ concentrations do not always correlate with portal-vein $\mathrm{NH}_{3}$ concentrations (Chamberlain \& Choung, 1995; Parker et al. 1995), which may be seen as the 'signal' monitored by the animal and ultimately determining its diet selection in these instances.

We have proposed in the past, that it appeared that ruminant animals (pregnant ewes) were selecting their diet mainly on the basis of its eRDP : fermentable ME (fME) ratio, when they were given a choice between two slowly fermentable foods (Cooper et al. 1994). This in turn could result in an 'optimal rumen function'. The diets selected by the sheep on the slowly fermentable food (choice $S_{L} / S_{H}$ ) in the present experiment had an almost identical eRDP: fME ratio to that in the experiment of Cooper et al. (1994): $11.4 \mathrm{~g}$ eRDP/MJ fME. However, sheep offered a choice between the two rapidly fermentable foods $\left(R_{L} / R_{H}\right)$ selected a diet with a higher $\mathrm{eRDP}: \mathrm{fME}$ value $(13.4 \mathrm{~g} / \mathrm{MJ})$. This perhaps suggests that the proposed ratio is not a sufficiently adequate description of food characteristics in terms of diet selection, since it does not provide any information on the rates of carbohydrate fermentation. As a consequence, it cannot be used as an adequate measurement of the synchrony between the rates of carbohydrates and $\mathrm{N}$ digestion, which is taken to account for the diet selection of the sheep in the present experiment.

When the results from the daily food intake and diet selection of animals on feeding treatments $S_{L}, S_{H}$ and choice $S_{L} / S_{H}$ are taken together, they suggest that animals might avoid, to a certain extent, a food $\left(\mathrm{S}_{\mathrm{H}}\right)$ due to (some) of its properties, in a choice feeding situation, while they consume considerable amounts of it when it is offered singly. This suggestion is consistent with previous findings, where animals selected against a urealoaded food (Kyriazakis \& Oldham, 1993) or a toxic (high in glucosinulates) one (Kyriazakis \& Emmans, 1992), despite the fact that they readily achieved high intakes on these foods when they were offered on their own singly. Thus, the trade-offs in the feeding behaviour of animals might be different when they are given access to one food rather than two foods as a choice.

Given the effect of dietary manipulation (food composition) on the diet selection of sheep, we were further expecting that short-term (over $4 \mathrm{~h}$ ) infusions of either urea or fructose would similarly affect the short-term diet selection of sheep. Following the same arguments as the ones advanced to account for their long-term diet selection, one could, for example, hypothesize that the infusion of fructose into the rumen of the animals given a choice between $S_{L}$ and $S_{H}$ foods, would result in the selection of a higher proportion of the high eRDP food, $S_{\mathbf{H}}$ in the short run. However, the rumen infusions had no effect on the 
diet selection of sheep, during any of the time intervals considered. This was despite the effect the infusions had on the rumen conditions measured ( $\mathrm{pH}$ and $\mathrm{NH}_{3}-\mathrm{N}$ concentration). We can offer three possible suggestions to account for this absence of an effect.

First, it is possible that, although rumen conditions were affected by the infusions (Fig. $3 b)$, they had either very slight or no consequences beyond the rumen. This could be of particular significance with the urea infusions, since the effects of rumen degradation of $N$ are mainly expected to be perceived beyond the rumen (Parker et al. 1995). This, however, seems an unlikely possibility to us, although we did not measure their consequences beyond the rumen. Infusion of urea into the rumen would have provided approximately $1.2 \mathrm{~g} \mathrm{~N} / \mathrm{h}$, which is almost double the eRDP supplied by the low eRDP foods (L), and a $50 \%$ increase over the eRDP supplied by the $\mathrm{H}$ foods.

Second, it is possible that ruminants are unable to respond rapidly to changes in their rumen environment, through tactical adjustments of food intake and diet selection. However, the outcome of such a strategy would be that the animal would be effectively prevented from achieving the aims of its overall feeding strategy, and it is contrary to the strategies adopted by animals in achieving other goals through their behaviour. We have also seen tactical adjustments over similar periods to these observed here both to food intake and diet selection, when the rumen $\mathrm{pH}$ or osmolality was affected by rumen infusions (Cooper et al. 1995a,b). The food intake adjustments of the sheep to the infusion of fructose (Table 3 ) further contradict this hypothesis.

Third, it is possible that the sheep were unable to associate the consequences of the rumen infusions with either of the foods offered as a choice, and hence they were unable to adjust their diet selection over the short period of $4 \mathrm{~h}$. Indirect support for this suggestion is provided by the fact that animals had received a training period of $10 \mathrm{~d}$ on the two foods, which was presumed sufficient to allow them to associate each food with its properties. On the other hand, each infusion was repeated only four times, and the experimental design did not allow any prior training for these experiences. This third, and preferred, hypothesis implies that the question of whether sheep are able to make tactical (short-term) adjustments in their diet selection in response to the rate of synchrony between the rates of fermentation of carbohydrates and degradation of protein, would need to be addressed through a different methodology from the one adopted here. Further indirect evidence for this hypothesis is also provided by the surprising consistency of the diet selection of the animals over the different time intervals considered. However, it has recently been suggested that there might be diurnal differences in diet selection, which mainly reflect the diurnal rhythm of feeding and rumination, especially the absence of feeding during darkness (Newman et al. 1994). Sheep appeared to prefer diets based on rapidly fermentable foods in the morning and slowly fermentable ones just before dark. The differences between the latter suggestion and our experimental results might lie in the type of choices offered to the animals: in our case they were unable to select diets with different fermentation characteristics within the day.

In conclusion, the present experiment suggests that the interactions between the rates of digestion of carbohydrates and $\mathrm{N}$ have an effect on the diet selection, at least in the long term, of sheep given a choice between two foods of different eRDP contents. Sheep select a daily diet from two foods of different eRDP contents, which avoids excess of eRDP. This degree of avoidance depends on the carbohydrate sources in the foods. However, further manipulation of this degree of synchrony in the rates of digestion of carbohydrates and $\mathrm{N}$, through short-term infusions, was unable to affect the diet selection of sheep in the shortterm. It is suggested that this was a reflection of the inadequate methodology (infusions) used to test the experimental hypothesis. 
This work was supported by funding from the Scottish Office Agriculture, Environment and Fisheries Department. We are grateful to Messrs D. H. Anderson and T. McHale for their expert technical assistance and to Dr M. Lewis for helping us with the formulation of the foods. Dr T. G. Papachristou and Mr T. Stegeman helped us with the statistical analysis of the first draft.

\section{REFERENCES}

Agricultural and Food Research Council (1992). Technical committee on responses of ruminant animals. Nutrition Abstracts and Reviews Series B 62, 781-835.

Agricultural and Food Research Council (1993). Energy and Protein Requirements of Ruminants. Wallingford: $\mathrm{CAB}$ International.

Chamberlain, D. G. \& Choung, J. J. (1995). The importance of rate of a ruminal fermentation of energy sources in diets for dairy cows. In Recent Advances in Animal Nutrition pp. 3-27 [P. C. Garnsworthy and D. J. A. Cole, editors]. Nottingham: Nottingham University Press.

Cooper S. D. B., Kyriazakis, I., Anderson D. H. \& Oldham, J. D. (1995a). The ability of sheep to modify their feeding behaviour in order to counteract challenges to their rumen environment. Animal Science 60, 513.

Cooper S. D. B., Kyriazakis, I. \& Nolan, J. V. $(1995 b)$. Diet selection in sheep: the role of the rumen environment in the selection of a diet from two foods that differ in their energy density. British Journal of Nutrition 74, 39-54.

Cooper, S. D. B., Kyriazakis, I. \& Oldham, J. D. (1994). The effect of late pregnancy on the diet selections made by ewes. Livestock Production Science 40, 263-275.

Cropper, M. R. (1987). Growth and development of sheep in relation to feeding strategy. PhD Thesis, University of Edinburgh.

De Visser, H. (1993). Characterisation of carbohydrates in compound feeds. In Recent Advances in Animal Nutrition, pp. 19-38 [P. C. Garnsworthy and D. J. A. Cole, editors]. Nottingham: Nottingham University Press.

Emmans, G. C. \& Kyriazakis, I. (1995). The idea of optimisation in animals: uses and dangers. Livestock Production Science 44, 189-197.

Engku Azahan, E. A. \& Forbes, J. M. (1992). Effects of intranuminal infusions of sodium salts on selection of hay and concentrate foods by sheep. Appetite 18, 143-154.

Forbes, J. M. (1995). Voluntary Food Intake and Diet Selection in Farm Animals. Wallingford: CAB International.

Ketelaars, J. J. M. H. \& Tolkamp, B. J. (1992). Toward a new theory of feed intake regulation in ruminants. 1. Causes of differences in voluntary feed intake: critique of current views. Livestock Production Science 30, 269-296.

Krebs, J. R. \& McCleery, R. H. (1984). Optimisation in behavioural ecology. In Behavioural Ecology-An Evolutionary Approach, pp. 91-121 [J. R. Krebs and N. B. Davies, editors]. Oxford: Blackwell Scientific.

Kyriazakis, I. \& Emmans, G. C. (1992). Selection of a diet by growing pigs given choices between foods differing in contents of protein and rapeseed meal. Appetite 19, 121-132.

Kyriazakis, I. \& Emmans, G. C. (1995). The voluntary feed intake of pigs given feeds based on wheat bran, dried citrus pulp and grass meal, in relation to measurements of feed bulk. British Journal of Nutrition 73, 191-207.

Kyriazakis, I. \& Oldham, J. D. (1993). Diet selection in sheep: the ability of growing lambs to select a diet that meets their crude protein requirements. British Joumal of Nutrition 69, 617-629.

Newman, J. A., Penning, P. A., Parsons, A. J., Harvey, A. \& Orr, R. J. (1994). Fasting affects intake behaviour and diet preference of grazing sheep. Animal Behaviour 47, 185-193.

Oldham, J. D., Buttery, P. J., Swan, H. \& Lewis, D. (1977). Interactions between dietary carbohydrates and nitrogen in sheep. Journal of Agricultural Science, Cambridge 89, 467-479.

Parker, D. S., Lomax, M. A., Seal, C. J. \& Wilton, J. C. (1995). Metabolic implications of ammonia production in the ruminant. Proceedings of the Nutrition Society 54, 549-563.

Parsons, A. J., Newman, J.A., Penning, P. D., Harvey, A. \& Orr, R. J. (1994). Diet preferences of sheep: effects of recent diet, physiological state and species abundance. Journal of Animal Ecology 63, 465-478.

Robinson, D. L. (1987). Estimation and use of variance components. Statistician 36, 3-14.

Sinclair, L. A., Garnsworthy, P. C., Newbold, J. R. \& Buttery, P. J. (1993). Effect of synchronising the rate of dietary energy and nitrogen release on rumen fermentation and microbial synthesis in sheep. Journal of Agricultural Science, Cambridge 120, 251-263.

Sinclair, L. A., Garnsworthy, P. C., Newbold, J. R. \& Buttery, P. J. (1995). Effects of synchronising the rate of dietary energy and nitrogen release in diets with a similar carbohydrate composition on rumen fermentation and microbial protein synthesis in sheep. Journal of Agricultural Science, Cambridge 124, 463-472.

Visek, W. J. (1968). Some aspects of ammonia toxicity in animal cells. Joumal of Dairy Science 51, 286-295. 